\title{
Carbon/Phenolic Nanocomposites as Advanced Thermal Protection Material in Aerospace Applications
}

\author{
J. S. Tate, ${ }^{1}$ S. Gaikwad, ${ }^{1}$ N. Theodoropoulou, ${ }^{2}$ E. Trevino, ${ }^{1}$ and J. H. Koo ${ }^{3}$ \\ ${ }^{1}$ Texas State University-San Marcos, Ingram School of Engineering, 601 University Drive, San Marcos, TX 78666-4616, USA \\ ${ }^{2}$ Texas State University-San Marcos, Department of Physics, 601 University Drive, San Marcos, TX 78666-4616, USA \\ ${ }^{3}$ The University of Texas at Austin, Department of Mechanical Engineering, Austin, TX 78712, USA \\ Correspondence should be addressed to J. S. Tate; jt31@txstate.edu
}

Received 1 February 2013; Revised 21 May 2013; Accepted 21 May 2013

Academic Editor: Xuchun Gui

Copyright (C) 2013 J. S. Tate et al. This is an open access article distributed under the Creative Commons Attribution License, which permits unrestricted use, distribution, and reproduction in any medium, provided the original work is properly cited.

\begin{abstract}
Ablative nanocomposites were prepared by incorporating multiwall carbon nanotubes (MWCNT) into phenolic resin and then impregnating them into rayon-based carbon fabric. MWCNT were blended into phenolic resin at $0.5,1$, and 2 wt $\%$ loadings using a combination of sonication and high shear mixing to insure uniform dispersion of MWCNT. The composite test specimens were tested by using an oxyacetylene test bed (OTB) applying a heat flux of $1000 \mathrm{~W} / \mathrm{cm}^{2}$ for duration of 45 seconds. Composite specimens with $2 \mathrm{wt} \%$ MWCNT showed reduction in mass loss, recession in length, and in situ temperatures compared to control composites.
\end{abstract}

\section{Introduction}

Ablation is a process of material removal from a surface or other erosive process and usually associated with materials for space reentry vehicles and rocket nozzles. The ablative materials are used as thermal protection materials for rocket nozzles, space vehicles, and combustion chambers of rocket motors. These materials should withstand very high temperatures in the order of thousands of degrees Celsius, high thrust, and high impact. The final material should be able to form complex shapes and be as light as possible. Currently the main consumers of ablative materials are military, NASA, and commercial space launching company.

Intensive research on ablative materials began during the space race between the USSR and the USA in 1950s. Some of these research materials were made by universities, while some by private companies, such as Cytec Industries. The most popular material used in the United States, which is the standard material for NASA and other organizations, is MX-4926 manufactured by Cytec Engineered Materials. MX-4926 is a composite material composed of woven rayonbased carbon fiber, carbon black filler, and a phenolic resin matrix. Many research groups, such as Ho et al. [1] and Patton et al. [2], used MX-4926 material as the baseline for the development of polymer nanocomposite ablative materials in their research.

Ablative materials have progressed with the introduction of new materials and technologies. Since the late 1990s, nanotechnology has been a new frontier of the scientific community. Nanotechnology deals with particles which have at least one dimension on the nanometer scale [2]. Nanoparticles are materials which are in the purest form that have exceptional fundamental properties. Their high surface-areato-volume ratio, especially for nanotubes, makes them perfect ablative and reinforcement materials. Addition of proper nanoparticles in polymer matrix can enhance ablative and overall mechanical properties of polymer matrix composites. Therefore, many articles and reports have been published on effects of nanoparticles on ablative properties [1-7]. The typical nanoparticles used for ablatives are single and multiwall carbon nanotubes (SWCNT, MWCNT), carbon black, and nanoclays. Nanoparticles vary not only in mechanical and physical properties but also by price, availability, processability, and safety. The following paragraph reviews the literature discussing the effects of polymer nanocomposites on ablation properties. These nanoparticles in polymer 


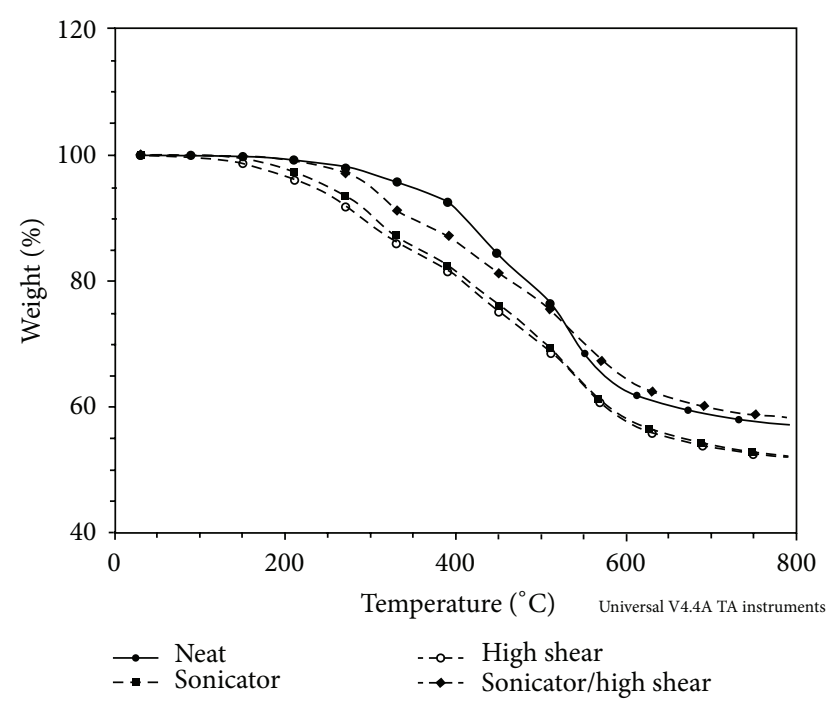

FIGURE 1: TGA analysis of phenolic resin samples containing $1 \mathrm{wt} \%$ MWCNT using different mixing techniques: sonication (SN), high shear mixing (HS), and combination of sonication and high shear mixing (SNHS).

resin include montmorillonite (MMT) organoclays, carbon nanofibes (CNF), multi-wall carbon nanotubes (MWCNT), and POSS.

Patton et al. modified carbon fiber-reinforced phenolic composites with carbon nanofibers (CNF). It was observed that the nanoscale dimensions of the vapor-grown CNF caused major changes in the heat transfer rates and affected the resultant combustion chemistry [8]. Liu et al. used POSS nanomodification in phenolic resin with carbon fiber reinforcement. SEM analysis showed the production of best charred surface on burnt samples that enhanced the ablation performance [9]. A novel flake graphite was introduced into barium-phenolic resin by Yu and Wan. Nanocomposites were made by roller-coating technology and its ablation property was tested under long pulse laser radiation. Nanocomposites showed better ablation performance compared to the control system. It was also observed that the size of the graphite flake affected the ablation rate [10]. Srikanth et al. prepared ablative nanocomposites by introducing nanosilica into the phenolic resin with carbon fiber reinforcement. Ablation resistance of nanocomposites increased with the nanosilica content up to $2 \mathrm{wt} \%$. However, beyond this point ablation resistance was decreased [11]. The ablation performance, thermal decomposition, and temperature distribution through the thickness of asbestos/phenolic composites modified with layered silicate were compared with traditional asbestos/phenolic composites by Bahramian and Kokabi [12]. Nanofillers were introduced at 3, 4, and $6 \mathrm{wt} \%$ loadings. Test samples were tested at the heat flux of $900 \mathrm{~W} / \mathrm{cm}^{2}$. The $6 \mathrm{wt} \%$ nanocomposite samples showed the best ablation performance [12]. Natali et al. produced two different mixtures, both consisting of $50 \mathrm{wt} \%$ phenolic matrix (PR) and $50 \mathrm{wt} \%$ nanofiller: one with carbon black (CB, Vulcan $7 \mathrm{H})$ referred to as $\mathrm{PR}-\mathrm{CB}$, constituted by $50 \%-\mathrm{PR}$ and 50\%-CB; the other with MWCNTs, constituted by $50 \%-\mathrm{PR}$ and $50 \%$-MWCNTs (Arkema Graphistrength
C100) referred to as PR-MWCNT. Their results included thermogravimetric analysis, evaluation of the heat capacity, oxy-acetylene test, and the postburning morphology. They observed better performance in nanomodified samples [1315]. Koo et al. prepared ablative nanocomposites by using MMT organoclay, POSS, and carbon nanofibers (CNF) with and without carbon fibers in a phenolic resin. The combination of high loading of MMT organoclay in phenolic resin, carbon fibers impregnated with phenolic resin, that is, modified using low loading of POSS, and high loading of CNF in phenolic resin showed better ablation performance than control carbon/phenolic composite [16].

For obtaining desired improvement in ablative properties, higher loading of MMT organoclays and CNF has to be employed. As wt $\%$ of nanoparticle increases, the viscosity of polymer resin increases rapidly. There is significant challenge in processing fiber reinforced composites using highly viscous polymer resins. On the other hand, lower loadings of MWCNT and POSS in polymer resin provide similar performance as that of higher loadings of MMT organoclays and CNF [13-16]. MWCNT are easier to produce and therefore are available in much larger commercial quantity at a more affordable price than POSS. The constant increase in production rate of MWCNT has significantly decreased the cost in recent years. Koo et al. provided a comprehensive review of literature on polymer nanocomposites as advanced ablative material. This review indicates that there are no attempts in developing composites consisting rayon-based carbon fabric, MWCNT, and phenolic resin [16].

The major objective of this research is to develop commercially viable ablative material that has significant improvement compared to current state-of-the-art (SOTA) ablative materials. The important factors for commercial success are cost, processability, and availability of all constituent materials in the composites. MWCNT are affordable. They are easy to process in polymer resin and available in sufficient commercial quantity. This paper describes the manufacturing and ablative performance of rayon-based carbon fiber reinforced composites using MWCNT modified phenolic resin. Ablative composites in this research are produced using exactly the same constituent materials: rayon-based carbon fabric and SC-1008 phenolic resin and exactly same manufacturing process as that of SOTA ablative material traded name as MX-4926.

\section{Materials and Methods}

This was a collaborative research with Cytec Engineered Materials (CEM). Carbon fiber reinforced nanocomposites were manufactured using processes and materials similar to those used by CEM for current SOTA ablative material, MX-4926. According to CEM description, MX-4926 MC (molding compound) is rayon precursor-based carbon fabric impregnated with MIL-R-9299 phenolic resin and carbon black as filler.

2.1. Fabric. Ablative test panels were manufactured using rayon-based 8-harness satin carbon fabric supplied by CEM. 


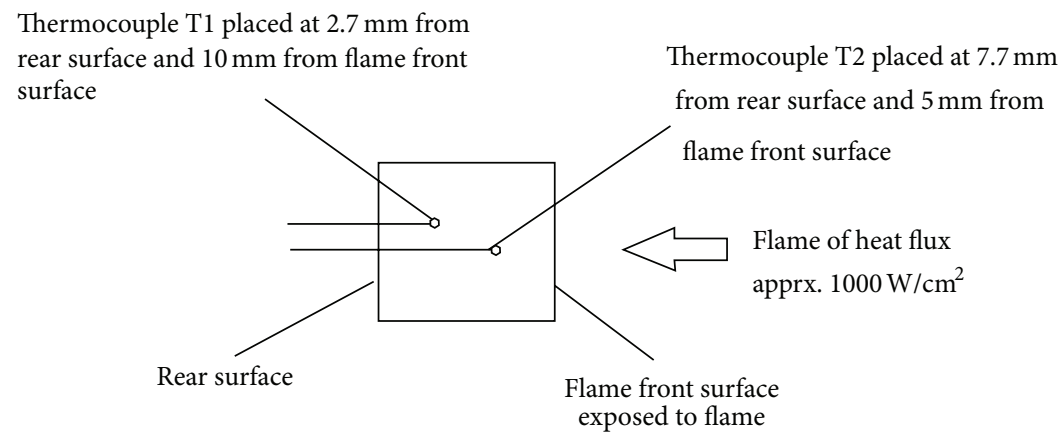

FIgURE 2: Placement of thermocouples in the ablative specimens.

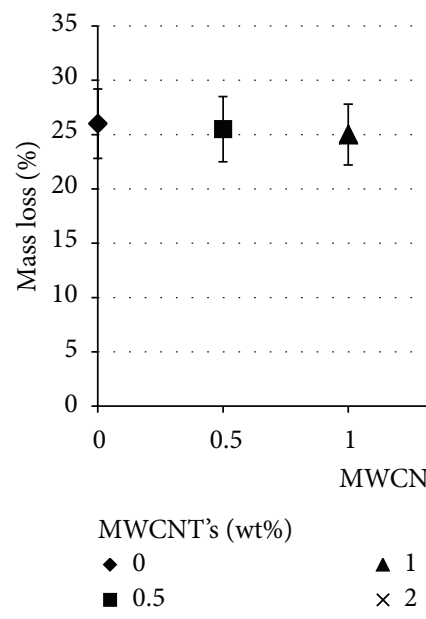

FIGURE 3: Decrease in percentage mass loss with increase in MWCNT wt\%.

The fabric had a weight of $261 \mathrm{~g} / \mathrm{m}^{2}$, specific gravity of 1.84 , and thickness of $0.48 \mathrm{~mm}$. Break strength was $0.496 \mathrm{MPa}$ and $0.599 \mathrm{MPa}$ in the warp and fill directions, respectively. It had 1.96 picks $/ \mathrm{mm}$ in warp direction and 2 picks $/ \mathrm{mm}$ fill direction. The 8 -harness satin weave provided conformability essential for producing complex geometries.

2.2. SC-1008 Phenolic Resin. The matrix used in this research was SC-1008 phenolic resin which was manufactured according to MIL-R-9299 and supplied by Momentive (formerly Hexion Specialty Chemicals). The viscosity was in the range of $180-300 \mathrm{cP}$ depending on storage conditions. SC-1008 contained roughly $20 \%-25 \%$ isopropyl alcohol (IPA) as a solvent. This is a phenolic-laminating varnish specifically designed for applications where components are exposed up to $260^{\circ} \mathrm{C}$ for extended duration of time.

2.3. Nanomodification. Nanomodification in ablative composites was achieved by incorporating Graphistrength MWCNT supplied by Arkema, Inc. They had a typical diameter of $10-15 \mathrm{~nm}$ and length between 1-10 $\mu \mathrm{m}$. MWCNT have tendency to agglomerate at dimensions of 50-900 $\mu \mathrm{m}$.

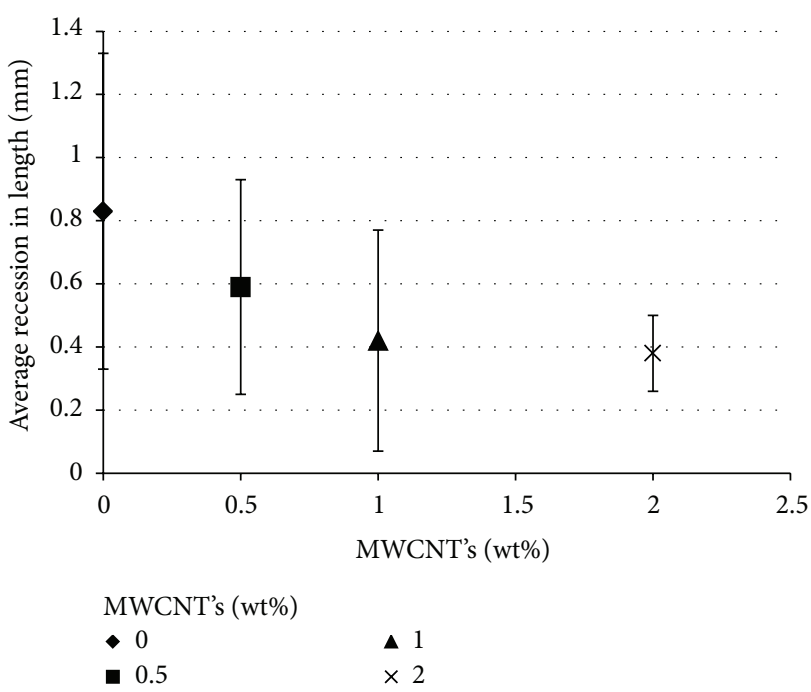

FIGURE 4: Decrease in recession with increase in MWCNT wt\%.

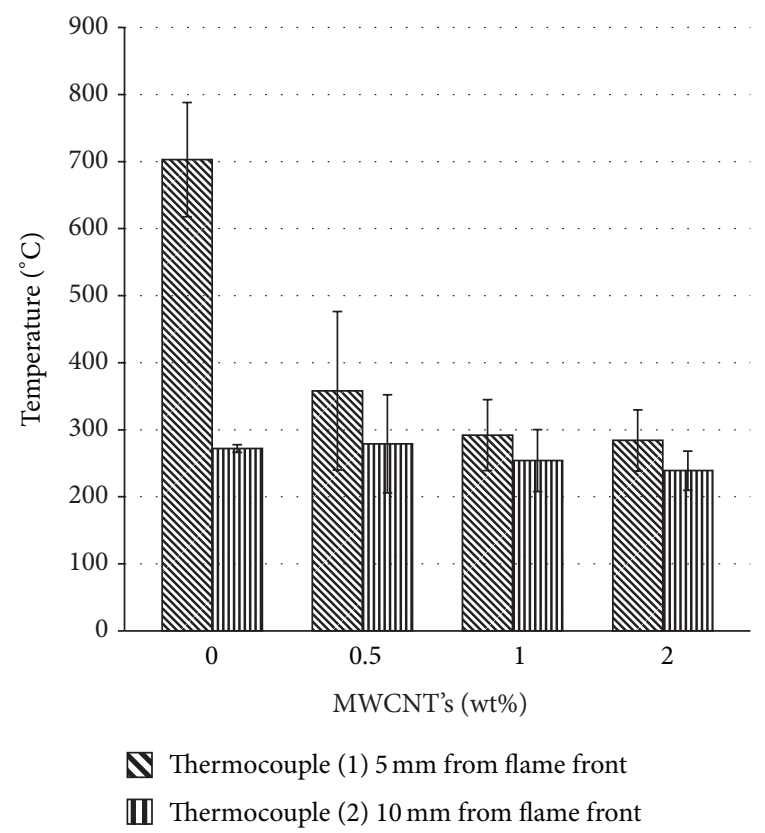

Figure 5: Peak in-situ temperatures at $5 \mathrm{~mm}$ and $10 \mathrm{~mm}$ depths from flame front surface. 


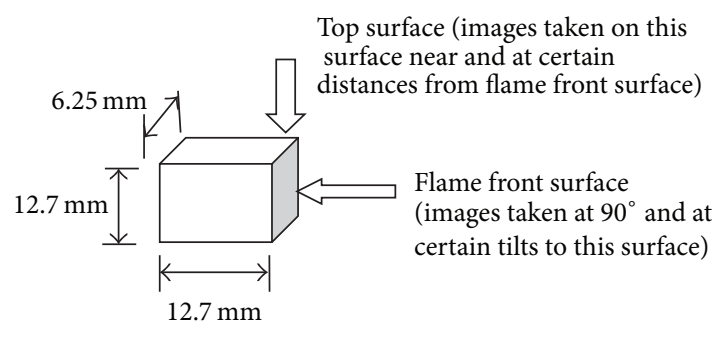

FIGURE 6: SEM Images on specimens after ablation testing.

Due to this agglomeration tendency, uniform dispersion of MWCNT was a very challenging task.

2.4. Dispersion of MWCNT into Phenolic Resin. In the previous studies by the same research team, $1 \mathrm{wt} \%$ MWCNT was dispersed into phenolic resin by using three different techniques: sonication (SN), high shear mixing (HS), and combination of sonication and high shear mixing (SNHS). To analyze the effect of dispersion of MWCNT in phenolic resin with respect to these different mixing techniques thermogravimetric analysis (TGA) was performed on all the samples. Characterization was carried out according to ASTM E 2550, the test method for thermal stability, and ASTM E 1131, the test method for compositional analysis. Samples were taken from a fractured surface of the phenolic coupons and had weights of $11.6-21.8 \mathrm{mg}$. All samples were placed in aluminum pans and heating was carried at a heating rate of $20^{\circ} \mathrm{C} / \mathrm{min}$, using argon as a purge gas at the rate of $100 \mathrm{~mL} / \mathrm{min}$. All samples were heated to a peak temperature of $800^{\circ} \mathrm{C}$. Use of inert atmosphere in TGA analysis is the key as MWCNT would oxidize in open air above temperatures $650^{\circ} \mathrm{C}$.

TGA showed that the majority of the mass loss for $\mathrm{SN}$ and $\mathrm{HS}$ samples was in the range of $200^{\circ} \mathrm{C}$ to $500^{\circ} \mathrm{C}$, while this range was $300^{\circ} \mathrm{C}$ to $550^{\circ} \mathrm{C}$ for SNHS samples. SNHS samples also showed better thermal stability for higher temperatures above $550^{\circ} \mathrm{C}$ as compared to other samples. Figure 1 shows TGA results for $1 \mathrm{wt} \%$ of MWCNT samples for all mixing methods. The plot clearly indicates that thermal stability of SNHS samples was better than the SN and HS samples. The higher temperature range for mass loss in SNHS samples is attributed to the increased dispersion of MWCNTs in the SC-1008 resin [17]. It can be inferred from TGA that the combination of sonication and high shear mixing (SNHS) processing technique provided uniform dispersion of MWCNT. Therefore, this technique was chosen to blend MWCNT into the phenolic resin.

Sonication was used to disperse MWCNT in IPA. Since SC-1008 contained IPA as the solvent, its usage as a dispersion medium was ideal. The amplitude of sonication varied between $25 \%-45 \%$ to compensate for subsequent increase in viscosity. The power of the sonicator was kept below 40 watts to avoid damaging the MWCNT and to prevent rapid build up of heat. Mixing could only proceed for two minutes before viscosity of the mixture increased, resulting in cessation of sonication. Then the resulted mixture was mixed with phenolic resin in a high shear mixer for 15 minutes at $40 \mathrm{~Hz}$ which provided shear rate of $77,000 \mathrm{~s}^{-1}$. A water cooling system was used to avoid overheating of the mixer and resin. The temperatures of the resin and mixing chamber were maintained below $50^{\circ} \mathrm{C}$. Three different loadings of MWCNT were introduced in the phenolic resin: $0.5,1$, and $2 \mathrm{wt} \%$. After high shear mixing, the resultant mixture was kept in a vacuum oven for 24 hours at $80^{\circ} \mathrm{C}$, so that excess IPA that was used for dispersion of MWCNT using sonication, got evaporated. It was observed that the viscosity increased very rapidly as the wt\% loading of MWCNT increased. Highly viscous resin imposes tremendous challenges in making prepregs using even hand lay-up technique. Carbon fabric must be completely soaked in the resin in order to maintain desired fiber volume percentage and density of the composite. Therefore, MWCNT loading was not increased beyond $2 \mathrm{wt} \%$.

2.5. Molding Compound Preparation. The second step of the manufacturing process was the production of prepregs using hand lay-up technique. Carbon fabric and resin were taken in proportion to achieve desired fiber volume fraction and density. Desired fiber volume fraction was $50 \%$ by volume. Carbon fabric was soaked with nanomodified phenolic resin using hand rollers. Prepregs were weighed after impregnation and then placed into a preheated oven at $100^{\circ} \mathrm{C}$ for 30 minutes to achieve B-staging. The prepregs were again weighed in order to evaluate mass loss. To prevent premature curing of the material, prepregs were stored into the freezer. Further these prepregs were manually cut into $12 \mathrm{~mm}$ by $12 \mathrm{~mm}$ squares using a cutting board.

2.6. Compression Molding. Ablative test panels were produced by compression molding using a Wabash Automatic Hydraulic Compression Press. Two-part compression mold with cavity of $120 \times 120 \times 12.7 \mathrm{~mm}(4.75 \times 4.75 \times 0.5$ inch $)$ was used for compression molding. The mold was made up of high alloy steel to withstand the high compressive forces. Appropriate mold release agent was used for smooth removal of panel after compression. The mold and the platens of the compression press were preheated to $163^{\circ} \mathrm{C}$. Small square pieces of prepregs were placed in the mold cavity, and then the mold was placed between the platens of compression press. Initially $45 \mathrm{kN}$ (5 US ton) force was applied for five minutes and then mold was released. Then $134 \mathrm{kN}$ (15 US ton) force was applied for 10 minutes. Finally, $267 \mathrm{kN}$ (30 US ton) force was applied for two hours at $163^{\circ} \mathrm{C}$ which provided pressure of $18.54 \mathrm{MPa}$ (2689 psi). Air and water cooling cycles were five minutes and 10 minutes, respectively. Specific gravity of ablative panel was measured. The target specific gravity was 1.46-the same as that of MX-4926. Density is one of the key properties of the ablative materials.

2.7. Preparation of Ablative Test Specimens. Ablative test specimens of size $12.7 \mathrm{~mm} \times 12.7 \mathrm{~mm} \times 12.7 \mathrm{~mm}$ cube were cut using a tile saw. Six specimens were cut in each category. Two holes of diameter $1.5 \mathrm{~mm}$ were made at depths $2.7 \mathrm{~mm}$ and $7.7 \mathrm{~mm}$ from the rear surface to place thermocouples during 


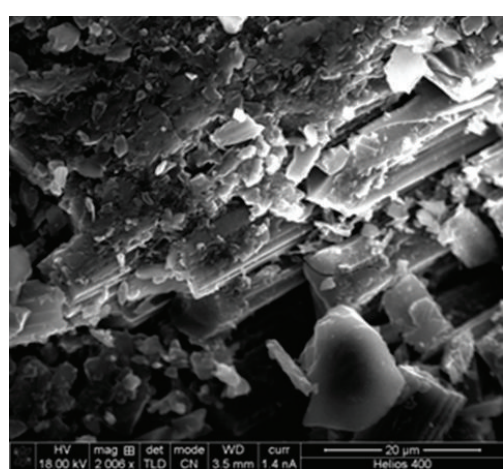

Top surface $(20 \mu \mathrm{m})$

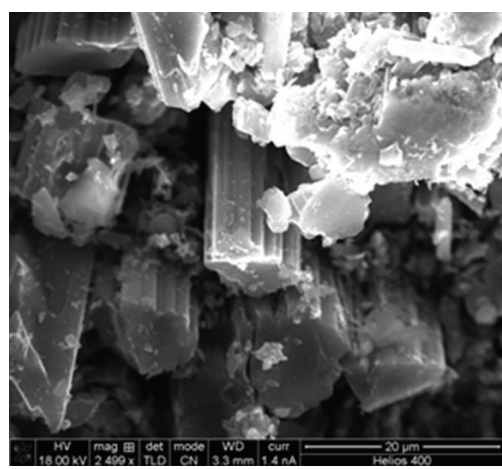

Top surface, $4 \mathrm{~mm}$ away from flame front $(20 \mu \mathrm{m})$

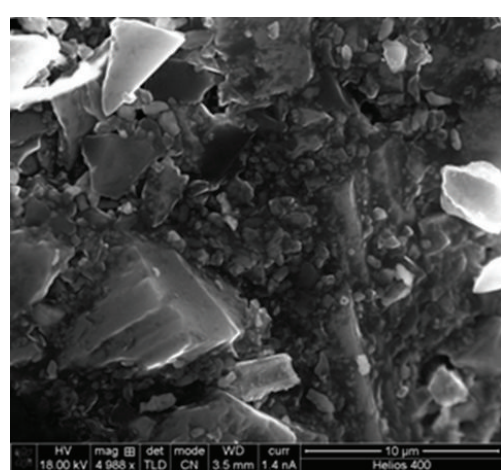

Top surface, $2 \mathrm{~mm}$ away from flame front $(10 \mu \mathrm{m})$

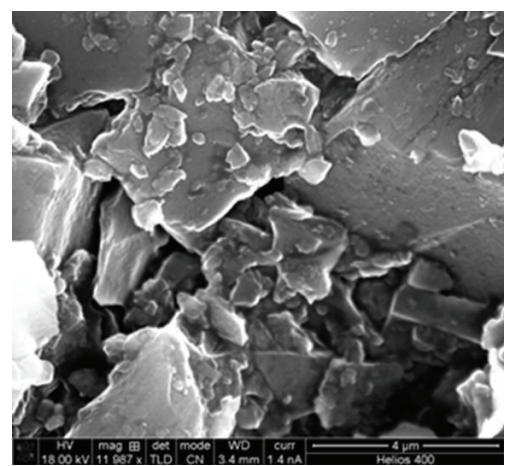

Top surface, $6 \mathrm{~mm}$ away from flame front $(4 \mu \mathrm{m})$

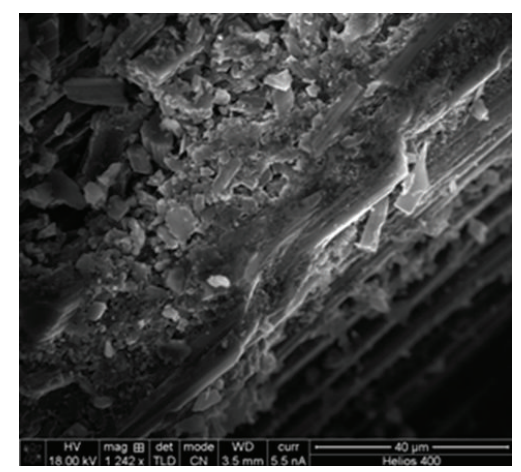

Flame front $(40 \mu \mathrm{m})$

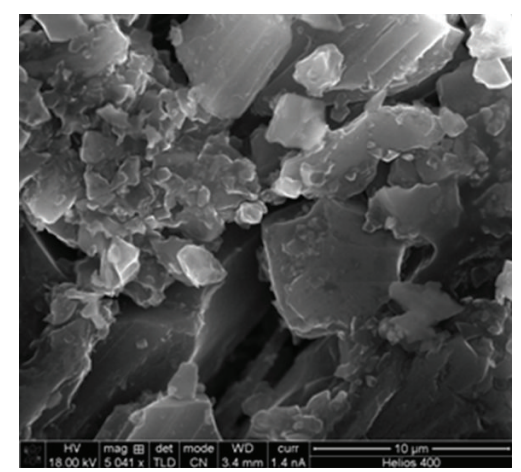

Top surface, $10 \mathrm{~mm}$ away from flame front $(10 \mu \mathrm{m})$

FIGURE 7: SEM images of control ablative samples.

testing. The distance between the holes was $2.5 \mathrm{~mm}$ as shown in Figure 2.

2.8. Testing of Ablative Specimens on Oxyacetylene Test Bed. The oxyacetylene test bed (OTB) is a small scale ablation testing device at the University of Texas at Austin, that is, capable of producing a heat flux of $1450 \mathrm{~W} / \mathrm{cm}^{2}$ and flame temperature up to $3000^{\circ} \mathrm{C}$ using a calibrated oxyacetylene welding torch. Similar types of devices have been developed at Sapienza University of Rome [18] and University of Perugia [19]. This type of experimental setup is used for testing different ablative materials at relatively low costs while still simulating extreme conditions in real world applications. It is suitable for comparing the relative performance of ablative materials to one another $[20,21]$.

OTB setup contains a data acquisition system to measure the in situ temperature of the test specimens using embedded thermocouples. The distance of the torch nozzle from the test specimen was used to calibrate the heat flux output of the OTB. A slug calorimeter was used to calculate these values in which a copper slug of known mass was exposed to the torch, and the power into the slug was derived from the measured time versus temperature curve of the slug $[20,21]$.

For this experiment, all materials were tested for duration of 45 seconds at a distance of $6 \mathrm{~mm}$ and applying approximately heat flux of $1000 \mathrm{~W} / \mathrm{cm}^{2}$. Six identical specimens were tested in each category. Masses and lengths of all test specimens were measured before and after the ablation test in order to measure the percentage mass loss and recession in length. Peak temperature at depths $2.7 \mathrm{~mm}$ and $7.7 \mathrm{~mm}$ from the rear face (which is $10 \mathrm{~mm}$ and $5 \mathrm{~mm}$ from flame front face) was obtained from the data acquisition system using thermocouples. Figure 2 shows the layout thermocouples on ablative test specimens.

\subsection{Postablation Scanning Electron Microscopy Characteri-} zation. Scanning electron microscopy (SEM) analysis was performed on all test specimens after ablation testing. High resolution SEM images were obtained at different orientations of the char microstructures in order to understand the effects of ablative testing on materials. SEM images were taken using Leo SRV-32 scanning electron microscope, under an argon gas atmosphere at different magnifications.

\section{Results and Discussions}

3.1. Ablation Test Results. Ablative test specimens were exposed to a heat flux of $1000 \mathrm{~W} / \mathrm{cm}^{2}$ for approximately 45 seconds. Results of percentage mass loss, recession, and peak in-situ temperatures presented herein are averages of six identical specimens tested in each category.

3.1.1. Percentage Mass Loss. All ablative samples were weighed before and after the ablation testing in order to 


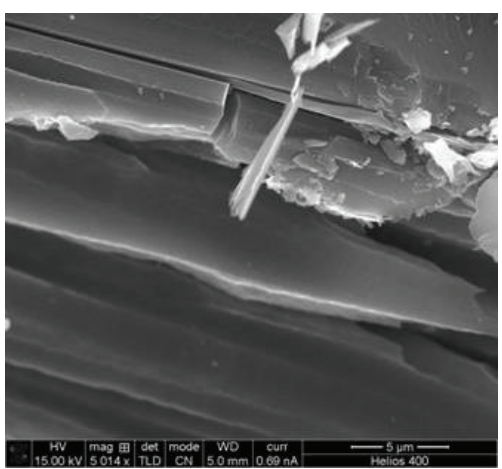

Flame front at with $45^{\circ}$ tilt $(5 \mu \mathrm{m})$

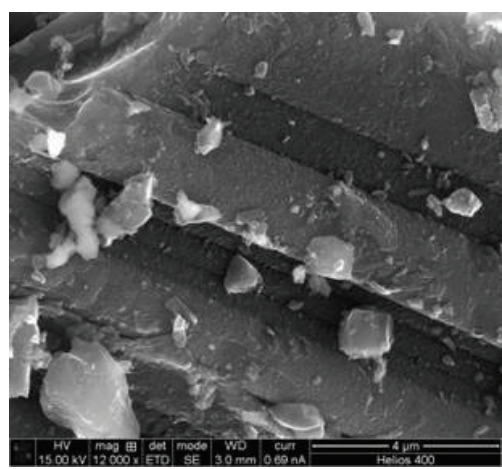

Top surface, $1 \mathrm{~mm}$ away from flame front $(4 \mu \mathrm{m})$

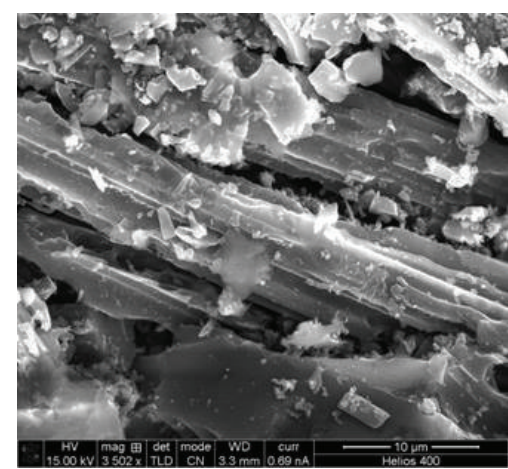

Top surface $(5 \mu \mathrm{m})$

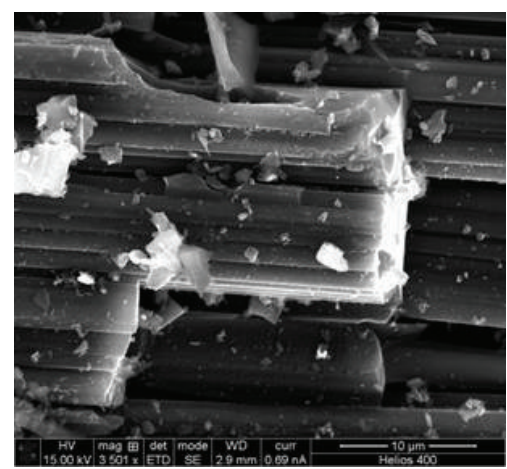

Top surface, $5 \mathrm{~mm}$ away from flame front $(10 \mu \mathrm{m})$

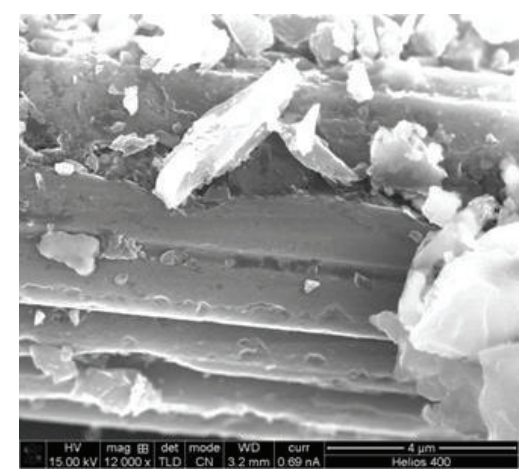

Top surface $(5 \mu \mathrm{m})$

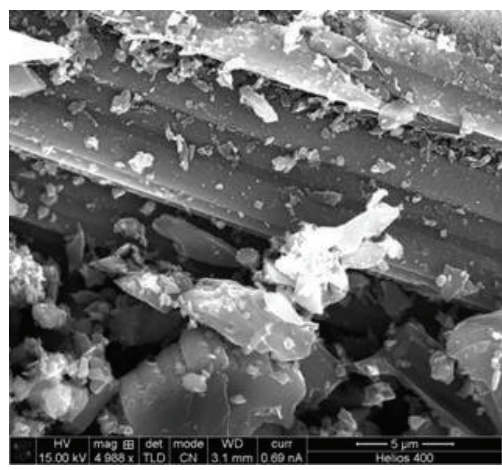

Top surface, $8 \mathrm{~mm}$ away from flame front $(5 \mu \mathrm{m})$

FIGURE 8: SEM images of $0.5 \mathrm{wt} \%$ MWCNTs ablative nanocomposite samples.

measure mass loss. It was observed that percentage mass loss for the ablative test specimens decreased with increasing MWCNT weight percentage. Results for percentage mass loss are shown in Table 1, and the decreasing trend of percentage mass loss is shown in Figure 3. All nanomodified test specimens showed better performance than control specimens. For control specimen, the percentage mass loss was $26 \%$, whereas it was $23 \%$ for composites containing $2 \mathrm{wt} \%$ of MWCNT. When a heat flux was applied on the specimens, initial heat transfer was by pure conduction and resulted in a temperature rise that caused material expansion. When the material reached a certain temperature, the pyrolysis reaction or thermochemical degradation occurred and produced decomposed gases and solid carbonaceous char residues [16]. In the nanocomposites, the nanoparticles formed highly viscous melt layer as soon as the pyrolysis reaction started, and it covered the formed char residue which acted as an antioxidizing agent and a thermal protective barrier forming a carbon-based network. This melt layer also continued endothermic reaction and reduced pyrolysis rate, resulting in less erosion of material [15]. In the case of MWCNT, their presence in char residue reemits large amount of incident radiation into gas phase, which decreased heat transferred to inner virgin material and reduced pyrolysis rate $[1,21]$. Hence, the addition of MWCNT resulted in decrease in percentage mass loss.
TABLE 1: Average percentage mass loss after ablation testing.

\begin{tabular}{lc}
\hline MWCNT wt\% & Percentage mass loss (\%) \\
\hline 0 & $26(3.2)$ \\
0.5 & $25.5(2.91)$ \\
1 & $25(3.09)$ \\
2 & $23(1.9)$ \\
\hline
\end{tabular}

Note: values in brackets indicate standard deviation.

3.1.2. Recession. The thickness of each specimen measured before and after the test was used to determine average recession. The thickness of samples measured after the ablation test was only thickness of virgin material, excluding char thickness. Recessions for nanocomposites were decreased with increasing MWCNT wt\%. Results for the recession are shown in Table 2 and decreasing trend of recession is shown in Figure 4. The recession of the control composite specimen was $0.83 \mathrm{~mm}$, whereas it was $0.38 \mathrm{~mm}$ for nanocomposites containing $2 \mathrm{wt} \%$ MWCNT. All nanocomposite specimens showed better performance than control material. The analysis of percentage mass loss and recession provided information about amount of material eroded or amount of material transformed into char. The decrease in percentage mass loss and recession are outcomes of improved thermal stability and the formation of a carbon network 


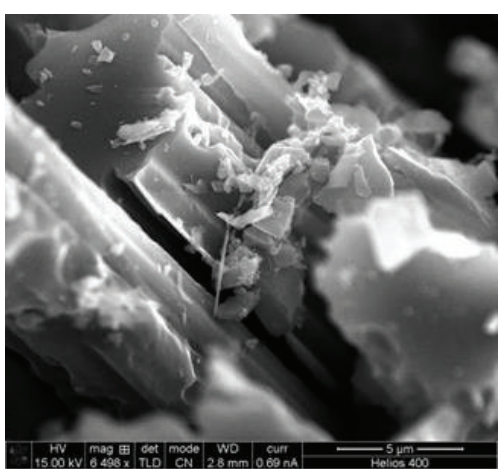

Flame front $(5 \mu \mathrm{m})$

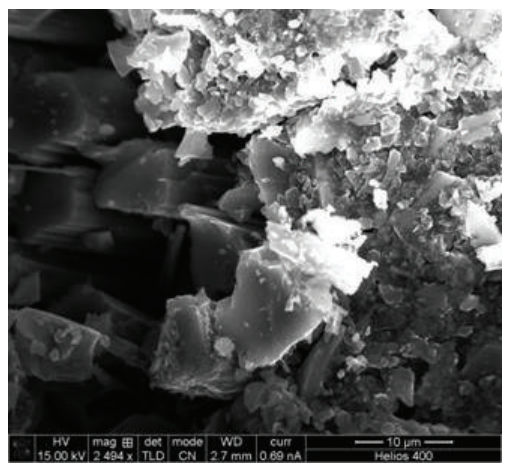

Top surface, $2 \mathrm{~mm}$ away from flame front $(10 \mu \mathrm{m})$

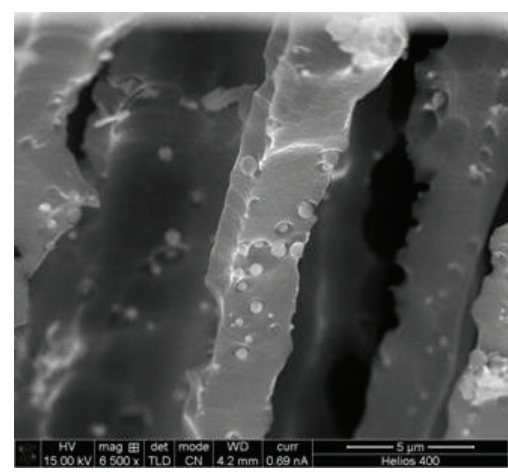

Flame front at $45^{\circ}$ tilt $(5 \mu \mathrm{m})$

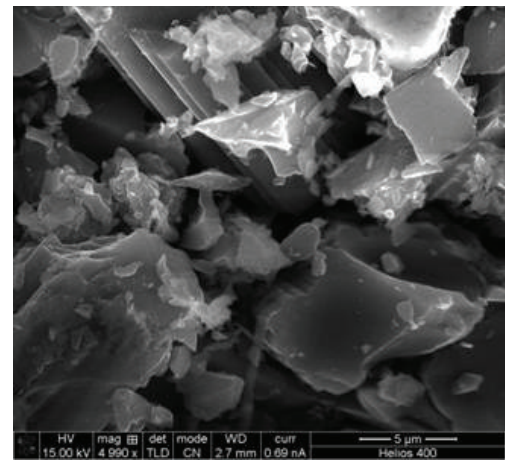

Top surface, $5 \mathrm{~mm}$ away from flame front $(5 \mu \mathrm{m})$

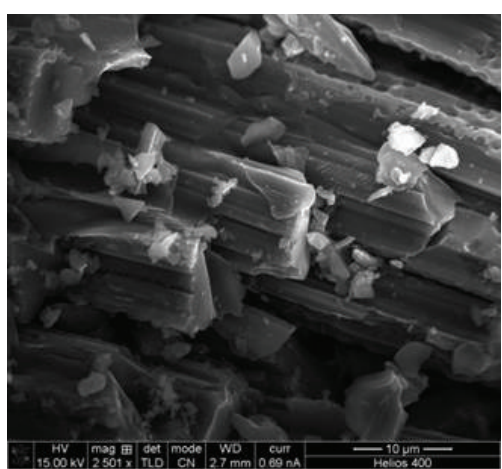

Top surface, $1 \mathrm{~mm}$ away from flame front $(10 \mu \mathrm{m})$

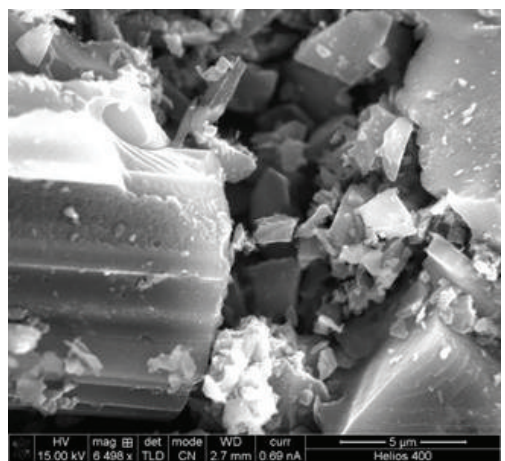

Top surface, $10 \mathrm{~mm}$ away from flame front $(5 \mu \mathrm{m})$

FIGURE 9: SEM images of $1 \mathrm{wt} \%$ MWCNTs ablative nanocomposite samples.

TABLE 2: Average recession after ablation testing.

\begin{tabular}{lc}
\hline MWCNT wt\% & Recession $(\mathrm{mm})$ \\
\hline 0 & $0.83(0.51)$ \\
0.5 & $0.59(0.35)$ \\
1 & $0.42(0.37)$ \\
2 & $0.38(0.12)$ \\
\hline
\end{tabular}

Note: values in brackets indicate standard deviation.

char achieved by addition of MWCNT. In control specimen, the absence of nanofillers led to continuation of pyrolysis reaction. This pyrolysis resulted in more erosion of material causing increased recession.

3.1.3. Peak In-Situ Temperature. During ablation testing, two K-type thermocouples, T1 and T2, were placed inside the specimens at depths of $2.7 \mathrm{~mm}$ and $7.7 \mathrm{~mm}$ from the rear face, respectively. Figure 2 shows the layout of thermocouples. These thermocouples were connected to the data acquisition system that provided temperature and time data during ablation testing. There are many factors that can affect the in-situ temperature in the specimens. Thermal conductivity of the material, char formed during testing, thickness of the virgin material, and char thickness affect the heat flow in the material [20]. Additionally, the eroded material also carried some heat which would have been conducted in the rest of the test specimen.

Figure 5 displays the average peak in-situ temperature decreased with increase in the wt $\%$ of MWCNT. Peak insitu temperature obtained from both the thermocouples at two different depths decreased with the increase in wt $\%$ of MWCNT. The average peak temperature obtained by thermocouple $\mathrm{T} 2$ at $5 \mathrm{~mm}$ from the flame front was $700^{\circ} \mathrm{C}$ for control test specimen, while it was significantly reduced to $284^{\circ} \mathrm{C}$ for nanocomposite containing $2 \mathrm{wt} \%$ of MWCNT. Similarly, the average peak temperature obtained by thermocouple $\mathrm{T} 1$ at $10 \mathrm{~mm}$ from flame front was $272^{\circ} \mathrm{C}$ for control test specimen, while it was reduced to $239^{\circ} \mathrm{C}$ for nanocomposite specimens containing $2 \mathrm{wt} \%$ of MWCNT. Figure 5 shows the decreasing trend of peak temperatures with increase in the wt $\%$ of MWCNT. There was little irregularity in the in-situ temperature decreasing trend for nanocomposite specimens containing $0.5 \mathrm{wt} \%$ MWCNT at $10 \mathrm{~mm}$ from flame front. The average peak in-situ temperature was a little higher at $279^{\circ} \mathrm{C}$ compared to $272^{\circ} \mathrm{C}$ for the control test specimen. The decreasing trends in the peak in-situ temperatures at both the depths were caused by the addition of MWCNT which led to high thermal stability and enhanced char formation of nanocomposite materials [22]. One of the reasons of increased thermal stability was due to enhanced carbon char formation and reradiation of MWCNT in phenolics. It is also 


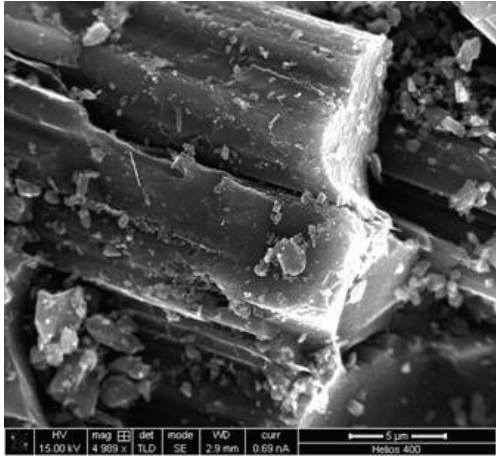

Flame front $(5 \mu \mathrm{m})$

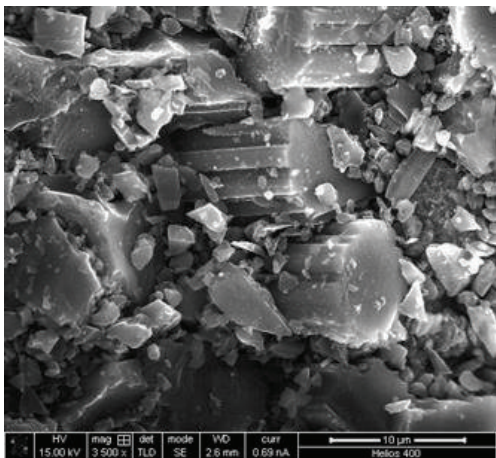

Top surface, $2 \mathrm{~mm}$ away from flame front $(10 \mu \mathrm{m})$

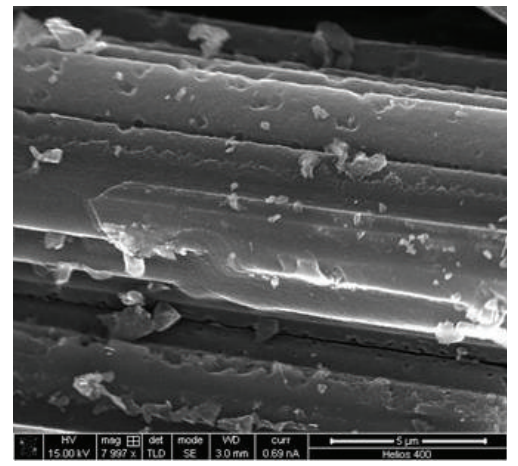

Flame front $(5 \mu \mathrm{m})$

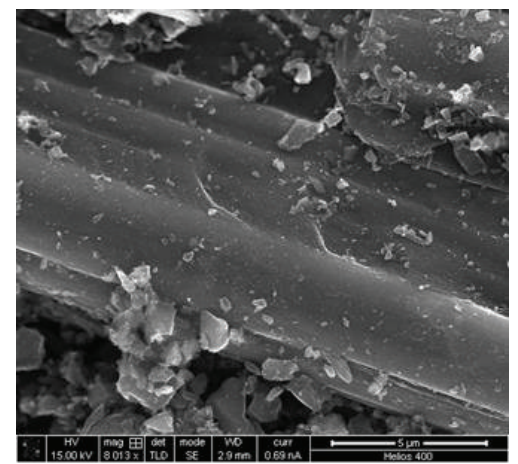

Top surface, $5 \mathrm{~mm}$ away from flame front $(4 \mu \mathrm{m})$

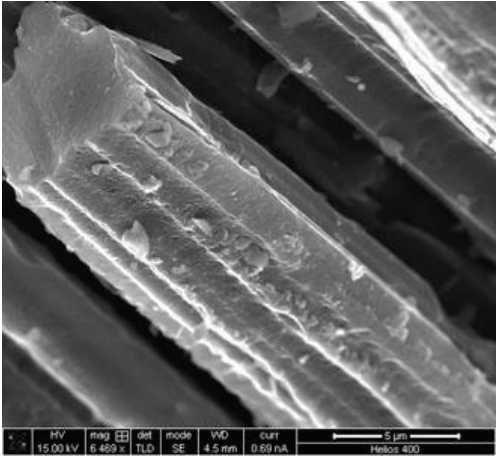

Flame front at $36^{\circ}$ tilt $(5 \mu \mathrm{m})$

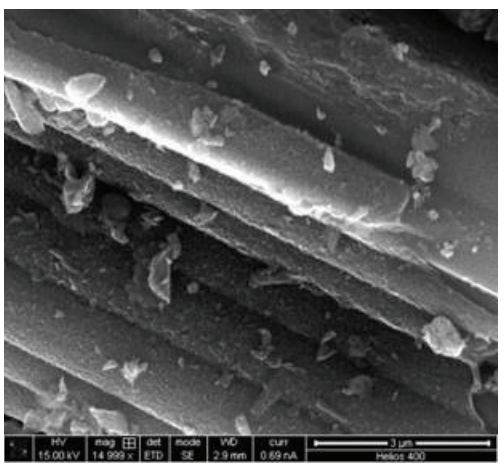

Top surface, $8 \mathrm{~mm}$ away from flame front $(3 \mu \mathrm{m})$

FIGURE 10: SEM images of $2 \mathrm{wt} \%$ MWCNTs ablative nanocomposite samples.

observed that the char produced in the nanocomposite test specimens contained MWCNT. The presence of MWCNT in the char led to formation of a homogenous carbonaceous char layer that worked as a heat shield during combustion. This heat shield prevented further passing of heat into the inner virgin material which resulted in reduced peak temperatures.

\subsection{Post-SEM Analysis. After ablation testing, test specimens} were cut into two halves, and SEM images on flame front and the top of cut surface were obtained. Flame front surface was also observed at certain degree tilt. Multiple images were taken on the top surface at distances of $2,4,6,8$, and $10 \mathrm{~mm}$ from flame front surface. Figure 6 provides details on how images were obtained. Figures 7 to 10 show the SEM images for control, $0.5,1$, and $2 \mathrm{wt} \%$ MWCNT composites, respectively. Figures 8,9 , and 10 show the clean appearance of MWCNT embedded in charred surface. These embedded MWCNT reemits large amount of incident radiation into gas phase during pyrolysis reaction, which led to decreased heat transfer into the inner layers [23,24]. Also, it can be inferred from the images that intensity of these MWCNT in charred surfaces increased with increase in the MWCNT wt\%. This resulted in the formation of the heat shield for the inner virgin material. In control test specimens, the char surface compromised of carbon fibers with phenolic matrix. Thus, there was no ceasing of pyrolysis reaction which resulted in the heating of inside layers and higher in-situ temperatures.

\section{Conclusions}

Ablative panels were successfully manufactured with phenolic resin, rayon precursor based carbon fabric, and MWCNT using similar procedure as that of Cytec Engineered Materials' MX-4926 MC (molding compound) ablative panels. The combination of sonication and high shear mixing was used for uniform dispersion and separation of individual MWCNT. Ablative test specimens were tested at a heat flux of $1000 \mathrm{~W} / \mathrm{cm}^{2}$ using the oxyacetylene test bed for 45 seconds. The test specimens were compared on the basis of percentage mass loss, recession, and peak in-situ temperatures at depths of $10 \mathrm{~mm}$ and $5 \mathrm{~mm}$ from flame front. The percentage mass loss for control test specimen was $26 \%$, whereas it was $23 \%$ for nanocomposite specimens containing $2 \mathrm{wt} \%$ MWCNT. Average recession was $0.83 \mathrm{~mm}$ for control test specimens, while it was reduced to $0.39 \mathrm{~mm}$ for nanocomposite specimens $2 \mathrm{wt} \%$ MWCNT. The peak in-situ temperatures at depths $10 \mathrm{~mm}$ and $5 \mathrm{~mm}$ from flame front showed decreasing trends as the MWCNT wt\% increased. Based on these results, it was concluded that the increase in wt $\%$ of MWCNT improved ablation and insulation performance of nanocomposites.

\section{Conflict of Interests}

None of the authors has any conflict of interests with these commercial companies, such as financial gain. 


\section{Acknowledgments}

The authors would like to thank Mr. Jon Weispfenning of Cytec Engineered Materials for providing technical support, Mr. Aram Mekjian of Mektech Composites for supplying SC-1008 phenolic resin, Mr. Evan J. Silo and Mr. Mark D. Finn of McLube for providing mold release agents, Mr. Blake Johnson of the University of Texas at Austin for helping in conducting ablation testing, and Mr. Ray Cook and Mr. Shane Arabie of Ingram School of Engineering at Texas State University for making compression molds. In this research, authors have used commercially available multiwall carbon nanotubes (MWCNT) from Arkema, Inc. The references of MMT organoclay, POSS, and carbon nanofibers (CNF) in this paper are primarily to provide the readers with what has been done. In the past, the authors also have used different nanoparticles, such as MMT organoclay, POSS, and CNF from commercial suppliers to evaluate their effects on ablative performance of composites.

\section{References}

[1] D. W. K. Ho, J. H. Koo, and O. A. Ezekoye, "Kinetics and thermophysical properties of polymer nanocomposites for solid rocket motor insulation," Journal of Spacecraft and Rockets, vol. 46, no. 3, pp. 526-545, 2009.

[2] R. D. Patton, C. U. Pittman Jr., L. Wang, J. R. Hill, and A. Day, "Ablation, mechanical and thermal conductivity properties of vapor grown carbon fiber/phenolic matrix composites," Composites A, vol. 33, no. 2, pp. 243-251, 2002.

[3] J. S. Tate, D. Kabakov, and J. H. Koo, "Carbon/phenolic nanocomposites for ablative applications," in Proceedings of International SAMPE Technical Conference, Salt Lake City, Utah, USA, October 2010.

[4] L. A. Pilato, J. H. Koo, G. E. Wissler, and S. Lao, "A reviewphenolic and related resins and their nanomodification into phenolic resin FRP systems," Journal of Advanced Materials, vol. 40, no. 3, pp. 5-16, 2008.

[5] A. V. Bray, G. Beall, and H. Stretz, "Nanocomposite rocket ablative material," Air Force Office of Scientific Research STTR Final Report, Spicewood, Tex, USA, 2004.

[6] J. H. Koo, L. A. Pilato, and G. E. Wissler, "Polymer nanostructured materials for propulsion systems," Journal of Spacecraft and Rockets, vol. 44, no. 6, pp. 1250-1262, 2007.

[7] M.-K. Yeh, N.-H. Tai, and Y.-J. Lin, "Mechanical properties of phenolic-based nanocomposites reinforced by multi-walled carbon nanotubes and carbon fibers," Composites Part A, vol. 39, no. 4, pp. 677-684, 2008.

[8] R. D. Patton, C. U. Pittman Jr., L. Wang, and J. R. Hill, "Vapor grown carbon fiber composites with epoxy and poly(phenylene sulfide) matrices," Composites A, vol. 30, no. 9, pp. 1081-1091, 1999.

[9] Y. Liu, Z. Lu, X. Chen, D. Wang, J. Liu, and L. Hu, "Study on phenolic-resin/carbon-fiber ablation composites modified with polyhedral oligomeric silsesquioxanes," in Proceedings of the 4th IEEE International Conference on Nano/Micro Engineered and Molecular Systems, pp. 605-608, Shenzhen, China, January 2009.

[10] Q.-C. Yu and H. Wan, "Ablation capability of flake graphite reinforced barium-phenolic resin composite under long pulse laser irradiation," Wuji Cailiao Xuebao/Journal of Inorganic Materials, vol. 27, no. 2, pp. 157-161, 2012.

[11] I. Srikanth, A. Daniel, S. Kumar et al., "Nano silica modified carbon-phenolic composites for enhanced ablation resistance," Scripta Materialia, vol. 63, no. 2, pp. 200-203, 2010.

[12] A. R. Bahramian and M. Kokabi, "Ablation mechanism of polymer layered silicate nanocomposite heat shield," Journal of Hazardous Materials, vol. 166, no. 1, pp. 445-454, 2009.

[13] M. Natali, M. Monti, J. Kenny, and L. Torre, "Synthesis and thermal characterization of phenolic resin/silica nanocomposites prepared with high shear rate-mixing technique," Journal of Applied Polymer Science, vol. 120, no. 5, pp. 2632-2640, 2011.

[14] M. Natali, M. Monti, J. M. Kenny, and L. Torre, "A nanostructured ablative bulk molding compound: development and characterization," Composites A, vol. 42, no. 9, pp. 1197-1204, 2011.

[15] M. Natali, M. Monti, D. Puglia, J. M. Kenny, and L. Torre, "Ablative properties of carbon black and MWNT/phenolic composites: a comparative study," Composites A, vol. 43, no. 1 , pp. 174-182, 2012.

[16] J. H. Koo, M. Natali, J. S. Tate, and E. Allcorn, "Polymer nanocomposites asablative materials-a comprehensive review," International Journal of Energetic Materials and Chemical Propulsion. In press.

[17] J. S. Tate, C. Jacobs, and J. H. Koo, "Dispersion of MWCNT in phenolic resin using different techniques and evaluation of thermal properties," in Proceedings of International SAMPE Symposium and Exhibition (ISEE '11), Long Beach, Calif, USA, May 2011.

[18] G. Pulci, J. Tirillò, F. Marra, F. Fossati, C. Bartuli, and T. Valente, "Carbon-phenolic ablative materials for re-entry space vehicles: manufacturing and properties," Composites A, vol. 41, no. 10, pp. 1483-1490, 2010.

[19] M. Natali, M. Monti, L. Torre, and J. M. Kenny, "Nanostructured ablative thermal protection systems," in Proceedings of International ECNP Conference on Nanostructured Polymers and Nanocomposites, Madrid, Spain, 2010.

[20] E. K. Allcorn, S. Robinson, D. Tschoepe, J. H. Koo, and M. Natali, "Development of an experimental apparatus for ablative nanocomposite testing," in Proceedings of 47th AIAA/ASME/SAE Joint Propulsion Conference, San Diego, Calif, USA, August 2011.

[21] E. K. Allcorn, M. Natali, and J. H. Koo, "Ablation performance and characterization of thermoplastic polyurethane elastomer nanocomposites," Composites A, vol. 45, pp. 109-118, 2013.

[22] J. J. George and A. K. Bhowmick, "Fabrication and properties of ethylene vinyl acetate-carbon nanofiber nanocomposites," Nanoscale Research Letters, vol. 3, no. 12, pp. 508-515, 2008.

[23] Z. Zhao and J. Gou, "Improved fire retardancy of thermoset composites modified with carbon nanofibers," Science and Technology of Advanced Materials, vol. 10, no. 1, Article ID 015005, 2009.

[24] S. S. Rahatekar, M. Zammarano, S. Matko et al., "Effect of carbon nanotubes and montmorillonite on the flammability of epoxy nanocomposites," Polymer Degradation and Stability, vol. 95, no. 5, pp. 870-879, 2010. 

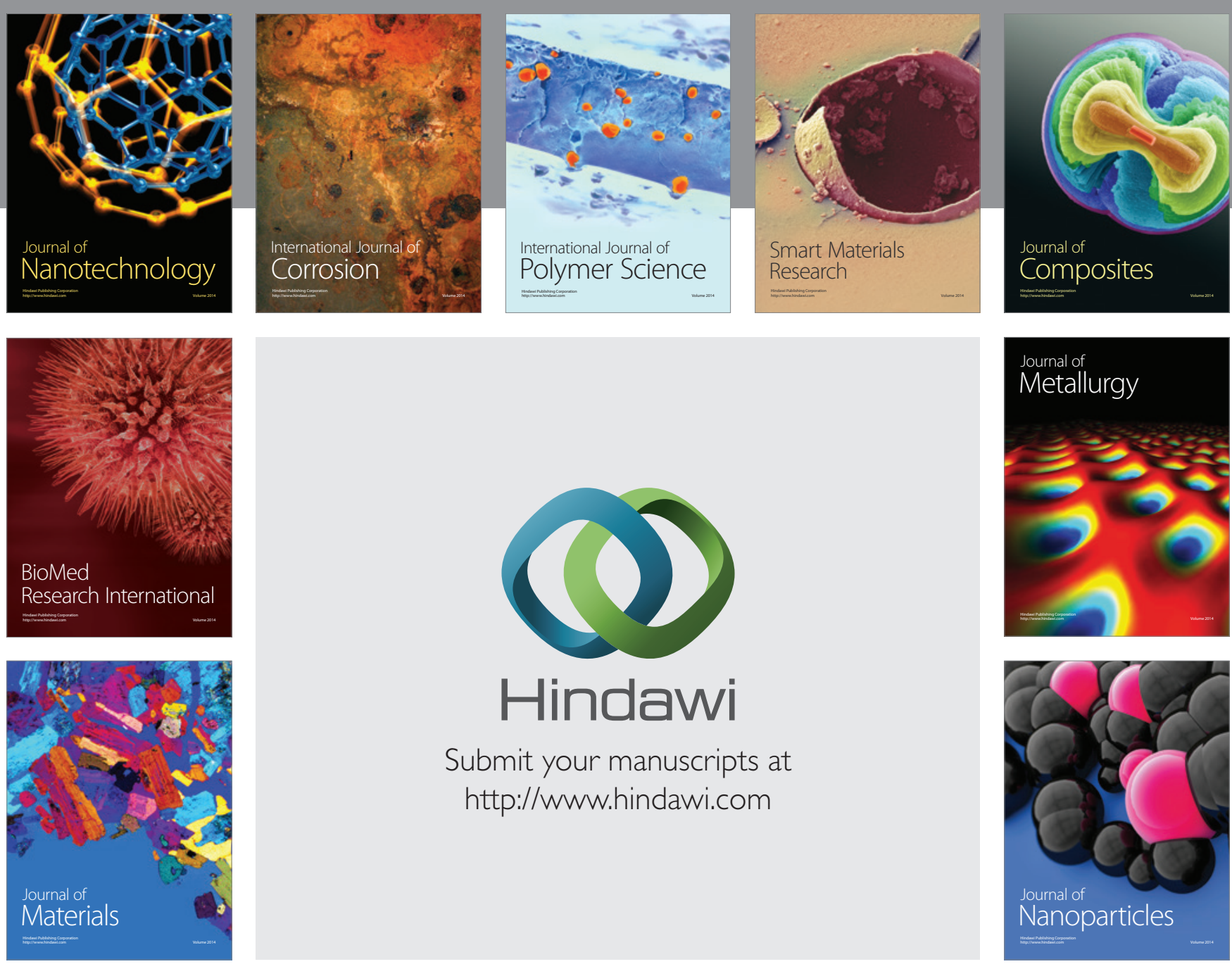

Submit your manuscripts at http://www.hindawi.com
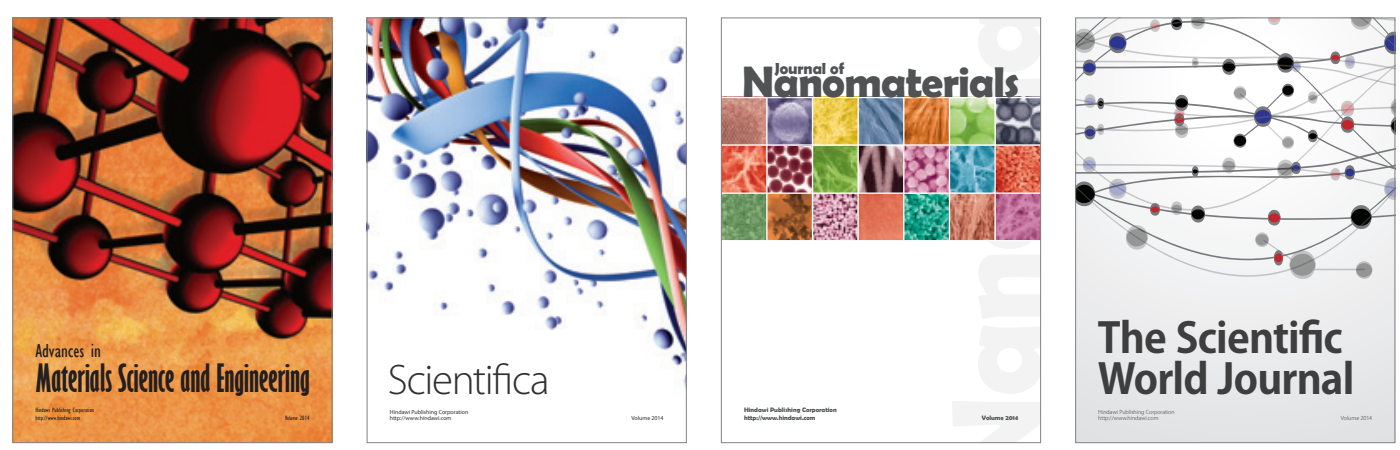

\section{The Scientific World Journal}
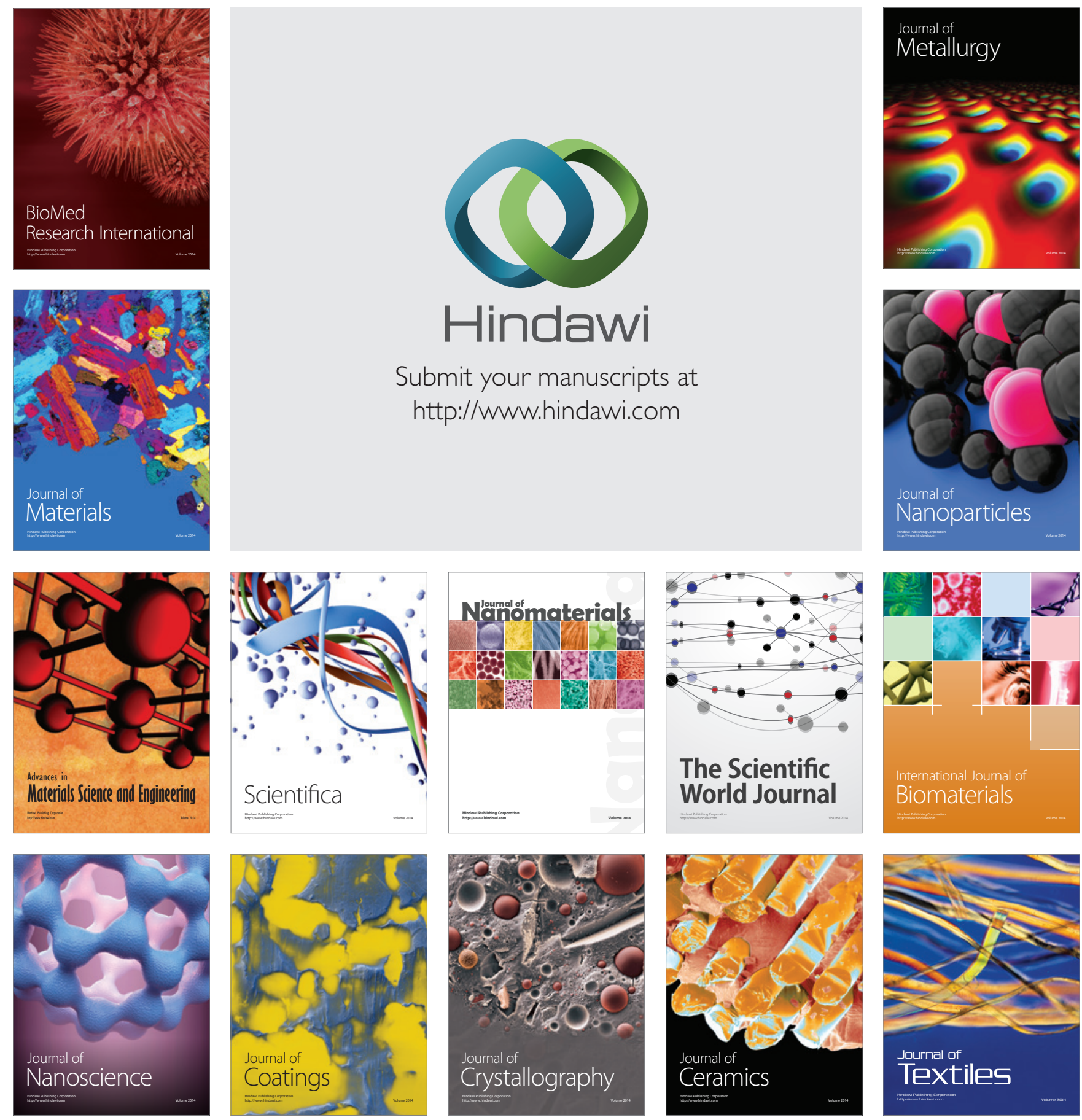